\title{
A weather dependent approach to estimate the annual course of vegetation parameters for water balance simulations on the meso- and macroscale
}

\author{
K. Förster, M. Gelleszun, and G. Meon \\ University of Braunschweig, Leichtweiss Institute for Hydraulic Engineering and Water Resources, \\ Department of Hydrology, Water Management and Water Protection, Beethovenstr. 51a, 38106 Braunschweig, Germany \\ Correspondence to: K. Förster (k.foerster@tu-braunschweig.de)
}

Received: 30 January 2012 - Revised: 5 July 2012 - Accepted: 11 October 2012 - Published: 11 December 2012

\begin{abstract}
In order to simulate long-term water balances hydrologic models have to be parameterized for several types of vegetation. Furthermore, a seasonal dependence of vegetation parameters has to be accomplished for a successful application. Many approaches neglect inter-annual variability and shifts due to climate change. In this paper a more comprehensive approach from literature was evaluated and applied to long-term water balance simulations, which incorporates temperature, humidity and maximum bright sunshine hours per day to calculate a growing season index (GSI). A validation of this threshold-related approach is carried out by comparisons with normalized difference vegetation index (NDVI) data and observations from the phenological network in the state of Lower Saxony. The annual courses of GSI and NDVI show a good agreement for numerous sites. A comparison with long-term observations of leaf onset and offset taken from the phenological network also revealed a good model performance. The observed trends indicating a shift toward an earlier leaf onset of 3 days per decade in the lowlands were reproduced very well. The GSI approach was implemented in the hydrologic model Panta Rhei. For the common vegetation parameters like leaf area index, vegetated fraction, albedo and the vegetation height a minimum value and a maximum value were defined for each land surface class. These parameters were scaled with the computed GSI for every time step to obtain a seasonal course for each parameter. Two simulations were carried out each for the current climate and for future climate scenarios. The first run was parameterized with a static annual course of vegetation parameters. The second run incorporates the new GSI approach. For the current climate both models produced
\end{abstract}

comparable results regarding the water balance. Although there are no significant changes in modeled mean annual evapotranspiration and runoff depth in climate change scenarios, mean monthly values of these water balance components are shifted toward a lower runoff in spring and higher values during the winter months.

\section{Introduction}

The global water cycle and vegetated land surfaces interact in a very complex way. Different types of computer models have to account the role of vegetated surfaces in the system of soil, vegetation and atmosphere. While Global Circulation Models (GCM) are in use to predict future climates in response to changing greenhouse gas concentrations, Regional Climate Models (RCM) provide future trends at the mesoscale. Water resources managers are interested in reliable information about future availability of water resources based on hydrologic models with input data from RCM. All these different models have to be parameterized for several types of vegetation. For this reason, model developers provide extensive look-up tables for their models. Both, model developers and also users are concerned with questions about an annual dependence of vegetation parameters. It is questionable whether these tables are valid for long-term simulations under changing climate conditions.

The observed climate change in the 20th century is mainly reflected by increasing temperatures. Affecting particularly the cryosphere, the observed trend in temperatures can lead to decreasing ice masses stored in glaciers as well as earlier 
melt and thus can cause a significant change in water availability (Barnett et al., 2005). Despite this very apparent influence of a changing climate, there is also evidence that climate affects vegetation and vice versa. Many time series of phenological observations are characterized by a significant shift toward an earlier beginning of the growing season (Chmielewski et al., 2004). These trends are not as apparent as the mentioned changes in the cryosphere but changes in the biosphere have to be accounted by climatologists and hydrologists. Menzel (2007) argues, that phenology is likely the easiest and best evaluated way to study the impact of climate change on ecosystems. In this citation a shift of 1.2 to 3.8 days per decade toward an earlier leaf onset in North America and Europe is reported.

Although there is little doubt about changing phenophases in response to the recent change in climate conditions, the prediction of these interactions between climate and phenology is challenging. A review on available types of phenologic models is also given in Menzel (2007). Most models use temperature-dependent or statistical approaches to represent spatial and temporal variability of plant properties. The application of more comprehensive, physiological models lags due to data availability and scaling issues.

Statistical approaches benefit from remote sensing techniques. Chen and Dudhia (2001) applied a monthly fiveyear climatology for the green vegetation fraction derived from AVHRR ("Advanced Very High Resolution Radiometer") observations in the Noah land surface model which is implemented in atmospheric models, e.g. in the Weather Research and Forecast Model (Skamarock et al., 2008). The revised Simple Biosphere (SiB2) approach (Sellers et al., 1996) is parameterized by analyzing normalized difference vegetation index (NDVI) data from AVHRR. However, Jolly et al. (2005) argue that these "fixed vegetation phenology parameters" neglect the characteristics of surface vegetation, which can be accomplished by considering climate variables as primary drivers. For example, the ecohydrologic model SWAT (Neitsch et al., 2009) combines the heat unit theory with management operations and a simple dormancy model considering day length whereas the model WaSiM-ETH (Schulla and Jasper, 2007) offers different types of modeling approaches which also incorporate soil moisture shortage. The new Noah land surface model with multiparameterization options (Niu et al., 2011) includes a complex dynamic leaf model which describes carbon budgets.

Jolly et al. (2005) suggest a simple approach which considers - despite of its simplicity - water vapor deficit and potential bright sunshine hours in addition to temperature. While at high latitudes with an oceanic climate the day length is the limiting factor for plant growth, in arid regions water supply for plants is restricted. As a surrogate Jolly et al. (2005) decided to account for water vapor deficit measurements rather than precipitation observations. From the mentioned variables a so-called "growing season index" (GSI) was calculated. Based on these findings Jolly et al. (2005) collected observations of the entire globe to create a map of the earth which depicts the spatial distributions of limiting factors for plant growth.

This paper addresses the applicability of the GSI approach for water balance simulations on the meso- and macroscale. Enhancements considering agriculture with a harvest approach are presented. Since the GSI is dependent on climate, the influence of a changing climate on the water balance can be studied.

\section{Data and methods}

\subsection{Study area}

The study area is the state of Lower Saxony in northern Germany. Most of Lower Saxony is located in the northern German plain. While the northern part is bounded by the North Sea coast, the southern part covers parts of the low mountain ridges, especially the Harz mountains with elevations up to $1000 \mathrm{~m}$ a.s.1. Thus, different climates of central Europe are captured ranging from maritime to continental, from coast to mountainous climates, which is especially interesting in respect to phenology. For long-term hydrologic simulations the upper Leine catchment (Reckershausen gauging station, $321 \mathrm{~km}^{2}$ ) in the south of Lower Saxony was chosen because the land-use $(60 \%$ agricultural areas with grain, rape and corn as well as $20 \%$ deciduous forests) is characteristic for the whole study area. Even though the Leine catchment is a low mountain ridge catchment, the elevation ranges from about 140 to $400 \mathrm{~m}$ a.s.1.

\subsection{Observational data}

Gridded datasets derived from meteorological observations were available on a daily time step (Haberlandt et al., 2011). These datasets include daily mean temperature, minimum and maximum temperature, relative humidity, wind speed and sunshine duration. Based on this input, daily GSI maps were created for the study area. These maps were used to derive the areal leaf onset for each year. Extensive phenological observations were provided by the German Weather Service (Deutscher Wetterdienst) to validate GSI derived leaf onset dates and to calculate trends. Areal observations of vegetation conditions were obtained from satellite data. MODIS (Moderate Resolution Imaging Spectroradiometer) vegetation indices 16-day L3 global $250 \mathrm{~m}$ (Huete et al., 2002; NASA, 2010) were available from the Terra satellite (beginning in 2000) and the Aqua satellite (beginning in 2002) in Hierarchical Data Format (HDF) which can easily be converted to common GIS formats.

\subsection{The GSI approach}

The growing season index combines a set of relevant meteorological variables which limit foliar phenology. Based 
on literature research the following variables on a daily time step were incorporated (Jolly et al., 2005): minimum temperature $T_{N}$, water vapor pressure deficit VPD, maximum day length (photoperiod) $t_{X}$. For each variable an index is calculated, which depends on threshold limits (see Fig. 1). The lower boundary $(\mathrm{min})$ of each variable indicates no phenological activity (index $=0$ ) whereas the exceedance of the upper boundary (max) is related to unconstrained growth. Between these boundaries the index is linearly interpolated. For example, a minimum temperature of $-2{ }^{\circ} \mathrm{C}$ (or below) indicates no phenological activity $\left(i T_{N}=0\right)$. If the minimum temperature is above $5{ }^{\circ} \mathrm{C}$, no constraints are assumed and $i T_{N}$ is 1 .

Figure 2 exemplarily illustrates how these variables limit phenology seasonally. The green domain refers to the time of the year when the maximum day length (photoperiod) leads to dormancy. There is no inter-annual variability of the maximum day length because it only depends on latitude of the site and the day of year. A mid-latitude site (as depicted) is in general characterized by limitations as a result of short day length during the winter. During springtime the day length increases while minimum temperatures typically still limit leaf onset. On cold days in spring the minimum temperature index often falls below 0.5. For arid climates (not shown here) water supply shortage can significantly affect plant phenology. Finally, all index values are combined to obtain the growing season index (Jolly et al., 2005). When considering the variability from day to day (as shown for the minimum temperatures), it is evident that this variability would cause distinctive fluctuations in the resulting GSI. Therefore, Jolly et al. (2005) propose a 21 days moving average of the GSI to obtain a smooth course for further evaluation in order to obtain the beginning and the end of the growing season. As a convention, in the following sections the GSI is a 21 day moving average of the value derived by Eq. (1):

$\mathrm{GSI}=i T_{N} \cdot i \mathrm{VPD} \cdot i t_{X}$

Jolly et al. (2005) validated the GSI on a global scale by comparing the GSI with satellite observations. For each climate station GSI time series were derived and compared to time series of the normalized difference vegetation index (NDVI). It was assumed that a comparison of observations on point scale and the corresponding pixel of satellite images is feasible. The calculation of the NDVI from optical satellite observations is a common approach to observe spatial and temporal patterns of vegetated surfaces. Since the radiative properties of vegetation differ when considering visible and near infrared, it is possible to distinguish between vegetated and non-vegetated surfaces by evaluating different wavelengths. Hence, the NDVI is defined by incorporating reflectances $\rho$ of visible (RED) and near infrared (NIR) wavelengths (Huete et al., 2002, Eq. 2):

$\mathrm{NDVI}=\frac{\rho_{\mathrm{NIR}}-\rho_{\mathrm{RED}}}{\rho_{\mathrm{NIR}}+\rho_{\mathrm{RED}}}$

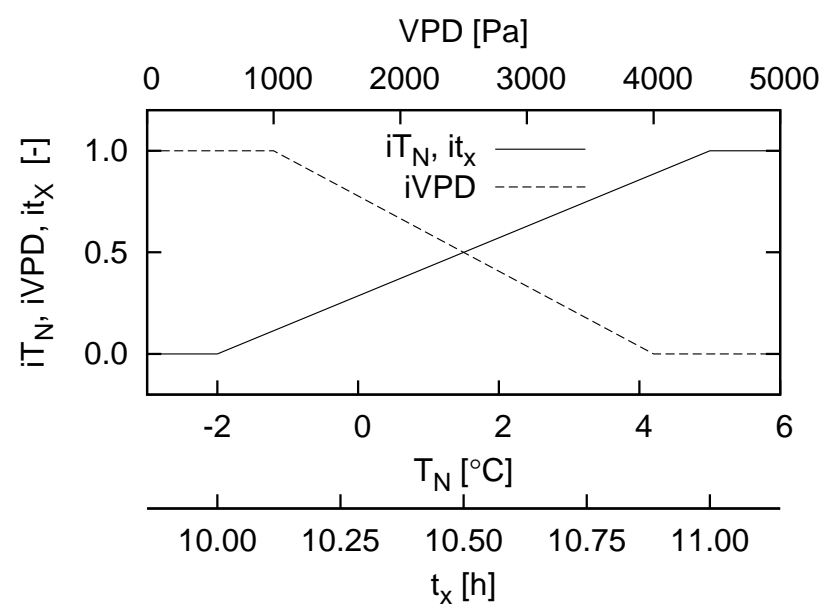

Fig. 1. Index functions for minimum temperature $i T_{N}$, water vapor deficit $i$ VPD and maximum day length $i t_{X}$ (Jolly et al., 2005). With these values the GSI can be calculated with Eq. (1).

In contrast to other land surfaces, water and ice, vegetation has relatively high NDVI values. Moreover, the NDVI is chlorophyll sensitive (Huete et al., 2002), which enables a monitoring of the vegetation state. Jolly et al. (2005) showed that both variables are comparable. GSI derived vegetation states can therefore be validated by comparing with NDVI time series. NDVI from MODIS MOD13 (Terra satellite) and MYD13 (Aqua satellite) observations are also depicted in Fig. 2. Observations with highest reliability classification have been considered to reduce uncertainty due to clouds and snow. The rising limb of the GSI time series accords very well to NDVI observations. The vicinity of Göttingen climate station is almost entirely agriculturally used. Thus, due to harvest NDVI decreases earlier than the GSI which only depends on meteorological variables. Following the argumentation of Itzerott and Kaden (2006), this effect refers to winter crops. On the basis of this example with agricultural influence it becomes evident that the original GSI approach is not applicable for agricultural use. A workaround to solve this problem is subject of the next section. At deciduous forest sites a better agreement of both time series has been observed. The falling limb is also reproduced well by the GSI approach. These findings emphasize that the GSI approach is a suitable tool to predict the annual course of vegetation parameters.

\subsection{Extensions to the original approach}

In order to use the GSI approach for hydrologic modeling the original assumption of GSI $>0.5$ for leaf onset is extended by a day-degree approach for agricultural areas. If the GSI exceeds a specified threshold, day-degree values are added up until they reach a plant specific threshold (see e.g., Miller et al., 2001) which corresponds to harvest. Comparisons with NDVI observations showed that a value of $1400^{\circ} \mathrm{C}$ is 


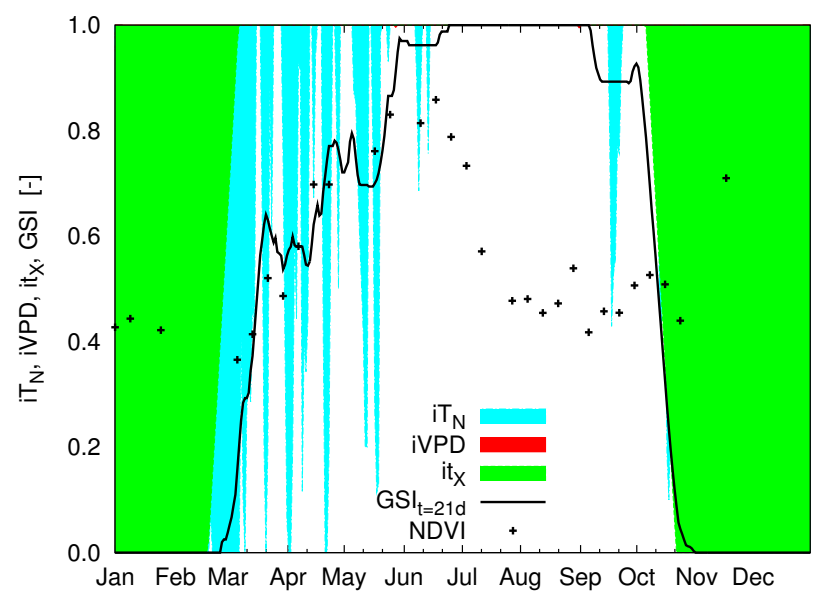

Fig. 2. Time series of the GSI for observations from Göttingen climate station (agriculture, latitude $51.50^{\circ} \mathrm{N}$, longitude $9.95^{\circ} \mathrm{E}$ ) for the entire year 2005. Filled areas indicate constraints due to low minimum temperatures, high water vapor deficit values or short day lengths.

suitable for the harvest of typical crops in the study area. The day-degree values are reseted to zero for a second phase, which is calculated in the same way as phase 1. Although this procedure is empirically derived by incorporating NDVI observations, it is also dependent on meteorological observations because its initiation within a year depends on a GSI threshold which is obtained by Eq. (1).

\subsection{The hydrologic model Panta Rhei}

Panta Rhei is a determistic, semi-distributed hydrologic model for single event or long-term simulations which has been developed at the University of Braunschweig (Riedel, unpublished data). Like other hydrologic models, Panta Rhei represents the watershed by subdivision into sub-catchments which consist of hydrologic similar units (HSU). Besides the typical dendritic arrangement of sub-catchments, junctions can be added to incorporate artificial channels. Moreover, reservoirs, retention structures, culverts and other features can be included into the watershed model. Because of Panta Rhei's flexible structure, the representation of hydrologic processes can easily be changed depending on the availability of input data and modeling purpose (see Table 1). A GIS interface enables a direct import of sub-catchment areas and properties in vector format. The simulation time step is specified by the user with typical values ranging from minutes and hours to one day. Currently, Panta Rhei is used for several kinds of applications which include hydrologic design, flood forecasting and climate impact studies. In the framework of this research study Panta Rhei was extended by the previously described GSI approach. For several land use classes plant parameters are provided which were compiled from literature studies (e.g., Breuer et al., 2003). The

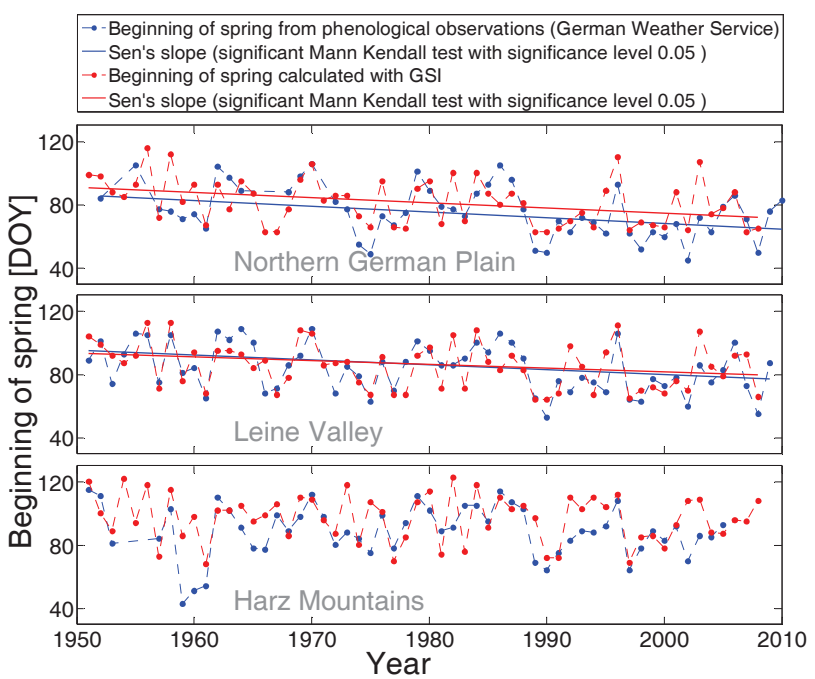

Fig. 3. Beginning of spring as observed (blue) and calculated (red) for three different sites in Lower Saxony.

GSI scales leaf area index (LAI), vegetation fraction, albedo and vegetation height on a daily time step, with minimum values referring to winter time and maximum values being valid at summer time, respectively. The time dependent parameters derived in such way are used then as input for the Penman-Monteith potential evapotranspiration module.

\section{Results}

\subsection{Comparison with phenological observations}

In this study it is assumed a priori that flowering of the goat willow (Salix Caprea) correspondents to GSI $>0.5$ (beginning of spring). Under these circumstances, the date of exceedance of the GSI threshold was compared to the dates of goat willow flowering. Figure 3 depicts the timeseries of observed and calculated beginning of spring for three different sites in the study area. Both, observed and calculated dates show a reasonable agreement. The range of observed dates (between day of year 40 and 120) was also reproduced by the model. Besides the course, the trends of the time series agree well $\left(-3\right.$ days decade $\left.^{-1}\right)$. It is worth to note that these trends are only observed in the lowlands (Northern German Plain and Leine Valley) rather than in the mountains. For the Harz Mountains neither the observed nor the calculated time series show a significant trend when using the Mann-Kendall test and Sen's slope method (Sen, 1968).

In addition to the comparison with NDVI observations which were used to adjust the original approach for agricultural use, the beginning of spring from phenological observations has also been reproduced by this simple model. This independent validation underlines the general applicability of the GSI approach for central Europe. 
Table 1. Representation of processes in Panta Rhei (adapted from Riedel, unpublished data).

\begin{tabular}{ll}
\hline Process & Description and available options \\
\hline Snow accumulation and melt & Temperature index approach, extended Anderson (1973) approach \\
Interception & Rutter et al. (1971) model, LAI scaled storage approach \\
Evapotranspiration & Priestley and Taylor (1972), Penman-Monteith approach (Monteith, 1965) \\
Infiltration and soil water balance & modified curve number approach (Riedel, 2004) \\
Runoff concentration & linear reservoirs for surface runoff, interflow and groundwater discharge \\
Runoff routing & linear and nonlinear cascade of reservoirs \\
\hline
\end{tabular}
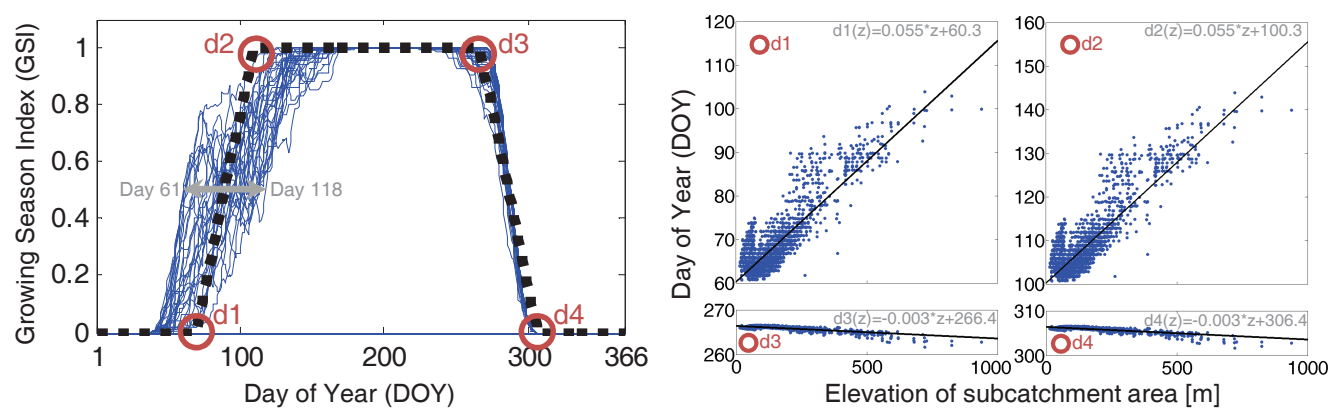

Fig. 4. Left panel: GSI courses of individual years and fitted mean GSI courses for an example sub-catchment. The points $d_{n}$ separate the mean course into 4 linear ranges which can easily be calculated from elevation. Right panel: values of $d_{n}$ were calculated for each subcatchment in south-eastern Lower Saxony (4500 in total). Regression functions were derived for each $d_{n}$ by plotting day of year for $d_{n}$ against sub-catchment elevation.

\subsection{Hydrologic simulation}

To evaluate the effect of dynamic adjusted vegetation parameters on water balance components two experiments were carried out. The first experiment uses a static parametrization approach neglecting inter-annual variability. Therefore, a mean annual GSI course was derived. To account for elevation-dependent shifts in phenological phases, a simple linear formulation of the GSI was derived (Fig. 4, left panel). The points $d_{n}$ represent the changes of phases. The elevation dependence was accomplished by incorporating the timeseries of the entire study area. The mean GSI course was evaluated for each sub-catchment (Fig. 4, right panel). In the second experiment the GSI is calculated by Eq. (1). Both, the static and the dynamic simulations include runs with time series from observations and from statistical downscaling of climate scenarios. The statistical downscaling was provided by the WETTREG2006 model which projects synoptic-scale circulations onto regional scales (Enke et al., 2005). For future climate simulations the A1B scenario was chosen. According to the Special Report on Emission Scenarios the A1B scenario "describes a future world of very rapid economic growth, global population that peaks in mid-century and declines thereafter, and the rapid introduction of new and more efficient technologies" by assuming a balance across all energy sources (IPCC, 2000). The simulations are herein subdivided into 4 periods: 20th century (20C, 1961-1990), which correspondents to the period of phenologic observations, and three future periods (2011-2040, 2041-2070, 2071-2100).

The results of the long-term water balance simulations are depicted in Fig. 5. In the left panel of Fig. 5 monthly runoff depth values are shown for several meteorological boundary conditions of the hydrologic model. Lines refer to the calibration including a comparison of observed and simulated runoff. The bars represent the runs with time series from statistical downscaling. It is worth noting that all simulations shown in Fig. 5 (left panel) are carried out with the static parameterization scheme, although all scenario runs were also accomplished with the dynamic approach (not shown here).

The differences in monthly runoff depth between the dynamic and the static experiment are opposed in Fig. 5 (right panel). Especially during springtime the calculated differences between the two experiments are negative, indicating that the runoff depth from the static experiment exceeds the runoff depth of the dynamic runs for all scenarios. In summer and autumn the difference moves closer to zero. In the winter months more runoff is simulated in the dynamic experiment. In general, future simulations tend to differ distinctively between both experiments. The differences of the observed time series runs indicate a bias between the experiments. Non-linearity of parameterization schemes (e.g., Penman-Monteith evapotranspiration scheme) in the hydrologic model is likely the source of this effect. Although all simulations rest on the same equations in both experiments the different annual courses of parameters affect results in 

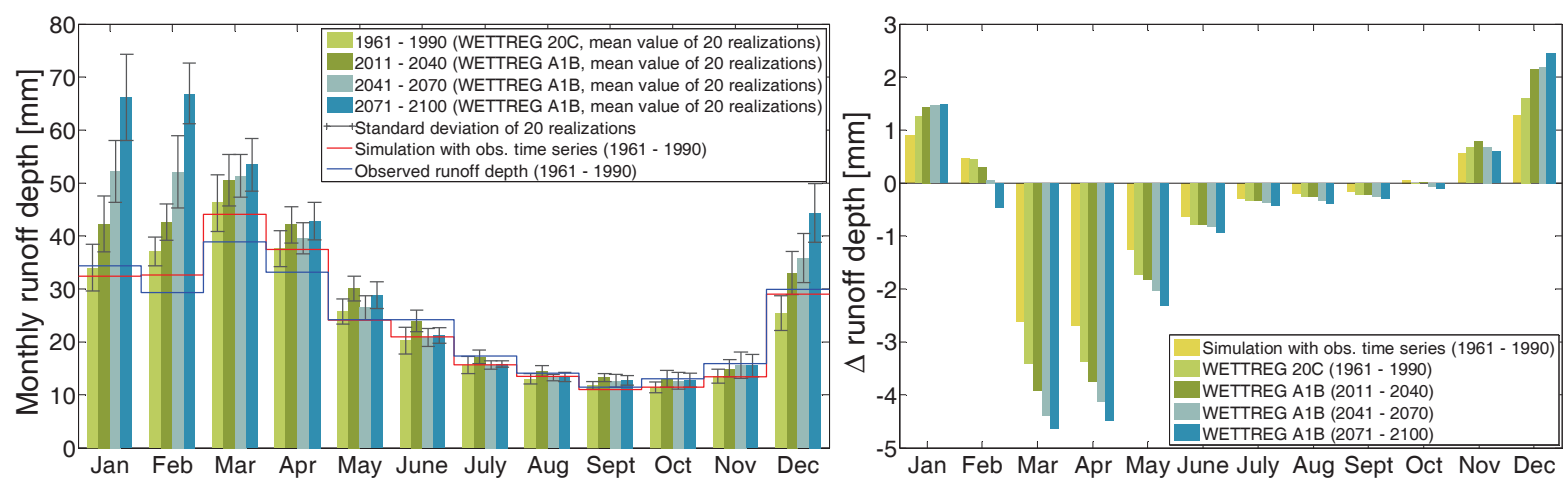

Fig. 5. Left panel: hydrologic simulation (monthly runoff depth) for different scenarios assuming a static, elevation-dependent vegetation course according to Fig. 4. Right panel: differences in simulated runoff depths between dynamic (GSI approach) and static parameterizations $(\Delta$ runoff depth $=$ dynamic-static $)$.

a range between -5 and $+2 \mathrm{~mm}$ month $^{-1}$. However, besides these model intrinsic effects, there is also a shift due to trends in meteorological boundary conditions (ranging from -2 to $+1 \mathrm{~mm} \mathrm{month}^{-1}$ ). The absolute differences between both experiments increase according to changing climate conditions. Mean annual runoff depth decreases from $394 \mathrm{~mm} \mathrm{a}^{-1}$ to $384 \mathrm{~mm} \mathrm{a}^{-1}$ when changing from static to dynamic parameterization in the A1B 2071 to 2100 run.

It is evident that a shift toward an earlier beginning of spring causes higher evapotranspiration rates, and hence lower runoff. In contrast, the positive values in the winter months could be addressed to the effect of a faster reaching of the day-degree thresholds in the extended approach. A trend in temperatures toward a warmer climate results in shorter growing times. An earlier harvest in the second phase also shifts the ending of the growing season to earlier dates in the year. Hence, vegetation parameters are changed to winter values. Since a major part of the basin is cultivatable land with two growing phases, this effect could dominate.

\section{Discussion and conclusions}

It was shown that the inter-annual variability and the trends of the observed growing season over the last decades can be reproduced by the GSI approach (Jolly et al., 2005). The simulated beginning of the growing season coincides well with phenological observations. In contrast to the lowlands where a trend toward an earlier beginning of the growing season was determined, both observed and simulated time series did not reflect a significant trend in the Harz Mountains. This finding could be explained by altitudinal differences in trends of the minimum temperature which is subject to further investigations.

In addition, the GSI approach was adapted to hydrologic modeling and extended for agriculturally used land surface classes. Thus, the model is capable to represent the influence of variability in growing season length on the evapotranspiration. In contrast to static methods, this approach is more suitable for climate impact studies, because the annual course of common vegetation parameters is derived in response to meteorological boundary conditions. Its simplicity enables an easy implementation, contrary to very complex dynamic leaf models.

The assumption of a moving average of 21 days as proposed by Jolly et al. (2005) was also used. Moving averages including future dates are not allowed for forecasting which restricts the GSI approach to long-term simulations. However, it could be shown that dynamic representation of vegetation parameters can affect water balance components. The annual runoff depth changed only by $2 \%$ but variations on a monthly basis reach up to $5 \%$ when changing from static to dynamic parameterization in this study. Future research should address the investigation of a wider range of basins and climates to understand the magnitude of possible differences.

Acknowledgements. This study was supported by the Ministry of Science and Culture of Lower Saxony (KLIFF - "Klimafolgenforschung in Niedersachsen"). Phenological observations were kindly provided by the German Weather Service (Deutscher Wetterdienst). The Terra and Aqua MODIS data were obtained through the online Data Pool at the NASA Land Processes Distributed Active Archive Center (LP DAAC), USGS/Earth Resources Observation and Science (EROS) Center, Sioux Falls, South Dakota, USA (http://lpdaac.usgs.gov/get_data). The Authors wish to thank Gerhard Riedel for his great work on developing hydrologic models. Another thanks is addressed to Ina Pohle and one anonymous reviewer for their helpful comments.

Edited by: K. Schneider and S. Achleitner

Reviewed by: I. Pohle and one anonymous referee 


\section{References}

Anderson, E. A.: National Weather Service River Forecast System - Snow Accumulation and Ablation Model, Silver Spring, MD, NWS HYDRO-17, NOAA Technical Memorandum, National Weather Service, 1973.

Barnett, T. P., Adam, J. C., and Lettenmaier, D. P.: Potential impacts of a warming climate on water availability in snow-dominated regions, Nature, 438, 303-309, 2005.

Breuer, L., Eckhardt, K., and Frede, H.-G.: Plant parameter values for models in temperate climates, Ecol. Model., 169, 237-293, 2003.

Chen, F. and Dudhia, J.: Coupling an Advanced Land SurfaceHydrology Model with the Penn State - NCAR MM5 Modeling System. Part I: Model Implementation and Sensitivity, Mon. Weather Rev., 129, 569-585, 2001.

Chmielewski, F.-M., Müller, A., and Bruns, E.: Climate changes and trends in phenology of fruit trees and field crops in Germany, 1961-2000, Agr. Forest Meteorol., 121, 69-78, 2004.

Enke, W., Schneider, F., and Deutschländer, T.: A novel scheme to derive optimized circulation pattern classifications for downscaling and forecast purposes, Theor. Appl. Climatol., 82, 51-63, 2005.

Haberlandt, U., van der Heijden, S., Verworn, A., Berndt, C., and Dietrich, J.: Regionalisierung von Klimabeobachtungsdaten und WETTREG-Szenarien für Niedersachsen als Grundlage für mittel- bis großskalige Modellierungen, Institut für Wasserwirtschaft, Hydrologie und Landwirtschaftlichen Wasserbau, Leibniz Universität Hannover, 2011.

Huete, A., Didan, K., Miura, T., Rodriguez, E., Gao, X., and Ferreira, L.: Overview of the radiometric and biophysical performance of the MODIS vegetation indices, Remote Sens. Environ., 83, 195-213, 2002.

IPCC: Special Report on Emissions Scenarios: A special report of Working Group III of the Intergovernmental Panel on Climate Change, Cambridge University Press, Cambridge, 2000.

Itzerott, S. and Kaden, K.: Ein neuer Algorithmus zur Klassifizierung landwirtschaftlicher Fruchtarten auf Basis spektraler Normkurven, Photogramm. Fernerkun., 6, 509-518, 2006.

Jolly, W. M., Nemani, R., and Running, S. W.: A generalized, bioclimatic index to predict foliar phenology in response to climate, Glob. Change Biol., 11, 619-632, 2005.

Menzel, A.: Phänologische Modelle, promet, 33, 20-27, 2007.

Miller, P., Lenier, W., and Brandt, S.: Using growing degree days to predict plant stages. Montana Guide Fact Sheet MT 200103 AG 7/2001, Montanta State University Extension Service, Bozeman, MT, available at: http://msuextension.org/ publications/AgandNaturalResources/MT200103AG.pdf (last access: 12 November 2012), 2001.
Monteith, J. L.: Evaporation and environment, The state and movement of water in living organisms, Symposia of the Society for Experimental Biology, edited by: Fogg, G. E., Vol. 19, 205-234, Cambridge University Press, Cambridge, 1965.

NASA: MOD13Q1, MYD13Q1, NASA Land Processes Distributed Active Archive Center (LPDAAC), USGS/Earth Resources Observation and Science (EROS) Center, Sioux Falls, SD, 2010.

Neitsch, S. L., Arnold, J. G., Kiniry, J. R., and Williams, J. R.: Soil Water Assessment Tool: Theoretical Documentation: Version 2009, available at: http://twri.tamu.edu/reports/2011/tr406. pdf (last access: 12 November 2012), 2009.

Niu, G.-Y., Yang, Z.-L., Mitchell, K. E., Chen, F., Ek, M. B., Barlage, M., Kumar, A., Manning, K., Niyogi, D., Rosero, E., Tewari, M., and Xia, Y.: The community Noah land surface model with multiparameterization options (Noah-MP): 1. Model description and evaluation with local-scale measurements, J. Geophys. Res., 116, D12109, 1-19, 2011.

Priestley, C. H. B. and Taylor, R. J.: On the Assessment of Surface Heat Flux and Evaporation Using Large-Scale Parameters, Mon. Weather Rev., 100, 81-92, 1972.

Riedel, G.: Ein hydrologisches Modell für tidebeeinflusste Flussgebiete, available at: http://www.digibib.tu-bs.de/?docid= 00001644 (last access: 12 November 2012), University of Braunschweig, 2004.

Riedel, G.: Panta Rhei User's Manual, University of Braunschweig, unpublished.

Rutter, A. J., Kershaw, K. A., Robins, P. C., and Morton, A. J.: A predictive model of rainfall interception in forests, 1 . Derivation of the model from observations in a plantation of Corsican pine, Agr. Meteorol., 9, 367-384, 1971.

Schulla, J. and Jasper, K.: Model Description WaSiM-ETH: Water balance Simulation Model ETH, available at: http://www. wasim.ch/downloads/doku/wasim/wasim_2007_en.pdf (last access: 12 November 2012), 2007.

Sellers, P. J., Tucker, C. J., Collatz, G. J., Los, S. O., Justice, C. O., Dazlich, D. A., and Randall, D. A.: A Revised Land Surface Parameterization (SiB2) for Atmospheric GCMs. Part II: The Generation of Global Fields of Terrestrial Biophysical Parameters from Satellite Data, J. Climate, 9, 706-737, 1996.

Sen, P. K.: Estimates of the Regression Coefficient Based on Kendall's Tau, J. Am. Stat. Assoc., 63, 1379-1389, 1968.

Skamarock, W. C., Klemp, J. B., Dudhia, J., Gill, D. O., Barker, D. M., Duda, M. G., Huang, X.-Y., Wang, W., and Powers, J. G.: A Description of the Advanced Research WRF Version 3, Vol. NCAR/TN-475+STR of NCAR Technical Note, Mesoscale and Microscale Meteorology Division, National Center for Atmospheric Research, Boulder, CO, 2008. 